Open Access

\title{
Challenges facing small-firm managers in growing manufacturing firms
}

Joakim Tell ${ }^{1,2}$

\author{
Correspondence: joakim.tell@hh.se \\ ${ }^{1}$ Center for Innovation, \\ Entrepreneurship and Learning \\ (CIEL), Halmstad University, Box \\ 82330118 Halmstad, Sweden \\ ${ }^{2}$ School of Business and \\ Engineering, Halmstad University, \\ Halmstad, Sweden
}

\begin{abstract}
Purpose: The purpose of this article is to better understand the management challenges facing managers in small growing firms.

Design/methodology/approach: Empirical data have been collected in Sweden through structured observations (approx. 20,000 min) of the working days of six top managers in fast- and six managers in slow-growing small manufacturing firms in order to compare managerial behaviour in two different contexts.

Findings: Managers in small firms are engaged in many different activities, but a small number of activities tend to take up the majority of the managers' time. These activities can be classified as either operational or administrative. There are notably small differences (both in variance and differentiation) between the behaviours of managers in fast- and slow-growing firms; actually, there are more similarities than differences. There is also surprisingly little time spent by the managers on strategic work, even in the group of fast-growing firms. This might explain why growth and innovation in many cases come to a halt or even decline in these firms and represents such a challenge for the managers when they do not prioritize strategic work.

Originality/value: The study shows that managerial work in small firms is characterized by a generic behaviour and that the managers mainly use a habitual and limited behavioural repertoire. Many managers have difficulties in changing their mainly operational and administrative behaviour and thus the underlying strategy of the firm. They are 'stuck' in a path-dependency mindset, even though the development of the firm might require another strategy taken by the manager, as a response to meet environmental demands.
\end{abstract}

Keywords: Managerial strategies, Observational studies, Habitual and limited behaviour, Path dependency, Innovation, Networks

\section{Background}

How is rapid small-firm growth described in the academic literature? In reviewing the literature, there are many different attempts made to explain this relation. Researchers from diverse disciplines are taking part in this quest and searching for explanations on many different analytical levels. Some have focused on the impact of factors in the environment of the small firm (e.g. Covin and Slevin 1989; Sadler-Smith et al. 2003; Iraj and Besnik 2011), while others have focused on the structure of the firm (Pelham and Wilsson 1995), and still, others have been concentrating on the significance of top managers (Wiklund 1998).

(c) 2015 Tell. Open Access This article is distributed under the terms of the Creative Commons Attribution 4.0 International License (http://creativecommons.org/licenses/by/4.0/), which permits unrestricted use, distribution, and reproduction in any medium, provided you give appropriate credit to the original author(s) and the source, provide a link to the Creative Commons license, and indicate if changes were made. 
One of the most influential and pioneering articles in this field was written by Birch (1979), who showed that fast-growing small firms are important when it comes to creating new jobs. Since then, there has been an ever-increasing interest in the relatively few small firms that grow fast and the question of what makes some small firms ${ }^{1}$ grow while the bulk of them do not and why it is so hard for small firms to continue and grow (for a conceptual review of the relationship between the manager and growth in small firms, see Andersson and Tell (2009)).

The focus in this article is on the analytical level of the leader, sometimes referred to as the upper-echelon perspective (Hambrick and Mason 1984), which contends that firm performance is a reflection of its manager, or as Morrison et al. (2003, p. 418) write concerning characteristics associated with growth in small firms: 'It would appear that there is a common, dominant thread woven through these characteristics, that is, the human factor of the owner manager'. The study of managers is well established, and that top managers have an effect on their firms' performance is an accepted proposition (e.g. Day and Lord 1988; Carpenter et al. 2004). Numerous studies have focused on this relationship from the perspective of managerial efficiency (Kotter 1982), business performance (Thomas 1988), and firm growth (Russel et al. 1994).

In focusing on the relationship between the manager and growth in small firms, three dominant views on and distinctions within this relationship seem to be presented in the academic literature (Andersson and Tell 2009, p. 589).

1. Whether it is something the manager has concretized as personal characteristics or traits (see for instance Gartner 1988)

2. Whether it is something the manager wants concretized as the motivation or the aspiration (see for instance Wiklund and Shepherd 2003)

3. Whether it is something the manager does, concretized as a behaviour (see for instance Gartner et al. 1992; Sarasvathy 2001 or Sadler-Smith et al. 2003)

These distinctions of the manager are well established in the academic literature concerning entrepreneurship and small businesses, and we found support of this in a large literature review conducted where we searched in more than 60 journals (see Anderson and Tell (2009)) for the relationship between the manager and growth in small firms.

A closer analysis of the research that focuses on top-management shows that the greater parts of the research have focused their explanatory proposals on leader characteristics and motivations. This analysis has been done using primarily quantitative methods and conducted from a trait perspective. Although some psychological traits have been found to be slightly more common among managers and entrepreneurs, research has shown that these people constitute a very heterogeneous group (Davidsson 1992).

From a theoretical point of view, this kind of explanatory approach has been exposed to some critique, and it has been suggested that research should be directed towards producing a better understanding of how leader behaviour affects small-firm performance (Gartner 1988; Gartner et al. 1992; Sarasvathy 2001; Sadler-Smith et al. 2003). It is only when characteristics/traits and motivation are put into action that they affect growth, or as Denison et al. (1995, p. 524) put it, 'Leadership must inevitably be performed through action, not cognition'. 
Additional critique has been directed towards this primary quantitative research from a methodological point of view; it has been argued that many aspects of the phenomenon of management and entrepreneurship are not very likely to be understood with quantitative and survey method techniques (Gartner et al. 1992, p. 26). Hence, it has been argued that research in this area should allow itself to deviate from its pursuit of 'rigorous research' and that researchers should spend more time with managers and entrepreneurs as part of the theory-building process (ibid., p. 22). This focus is also put forward as central in organizational behaviour management (OBM) studies, in order to understand effective organizational contingences (Houmanfar et al. 2009).

Wiklund (1998) brings up an interesting limitation of research focusing on management and entrepreneurial characteristics/traits, and that is that they have only an indirect effect on growth. If instead of focusing on defining the characteristics/traits of the manager, one follows the idea of Wiklund (1998), focusing on what the managers actually do and how this work relates to growth, it seems a promising way to reach an understanding of the relation between top-managers' work and growth. This view also opens the possibility of joining the research tradition of traits with studies that have focused on the behaviour/roles of the entrepreneur/top-manager (for instance Choran 1969 in Mintzberg 1973, Noel 1989, O'Gorman 2001, Florén and Tell 2004).

So, in spite of the fact that the growth phenomenon has been researched for some time, research is still relatively limited, and the phenomenon is still not very well understood (Hendrickson and Psarouthakis 1998; Simpson et al. 2012). Both from theoretical and methodological points of views, new approaches have been sought (Hales 1986, Tipu and Arain 2011).

The purpose of this article is to try to understand better the challenges facing managers by comparing the behaviour of managers in slow- and fast-growing small firms, in order to see how their behaviours differ and how these could be related to the growth of the firm, and why it is so hard for small firms to continue and grow.

\section{Theoretical framework}

What then constitutes the successful manager of a growing firm? Central to most theories and empirical findings in the literature concerning SME growth that try to explain the successful top-manager is something that is well cited by Denison et al. (1995, p. 525) as 'the notion that leaders can be classified in either one category or the other, or that certain styles and behaviors can be matched with certain situations to produce effective leadership'. However, this dichotomizing perspective has been criticized, and other approaches to studying leadership have been taken by, for instance, Slevin and Covin (1990) that sees upon leadership as situational.

From this perspective, successful companies are those which manage to cycle between different styles. The idea of seeing the phenomena as situational is also present in the leadership literature, where the general implication is that effective managers have the ability to both conceive and perform multiple and conceptually contradictory roles (Quinn et al. 1982; Denison et al. 1995; Hooijberg 1996), and which presents a more comprehensive way to describe the work of the managers.

From a situational theoretical perspective, the managers' interpretation of the internal culture of the company, as well as the external environment in which the company 
operates, a broad behavioural repertoire of leadership roles, and the frequent performance of conceptually contradictory roles seem to correlate to firm growth. 'Effective leaders are those who have the cognitive and behavioral complexity to respond appropriately to a wide range of situations that may in fact require contrary or opposing behaviors' (Hooijberg et al. 2001, p. 526).

So, from this theoretical perspective, it seems as if successful managers are those who manage to have a broad behavioural repertoire, compared with the less successful mangers' more limited repertoire. On the other hand, as seen from a management perspective, the business environment in which many companies operates is often described and perceived as increasingly complex, unpredictable, and unstable (one statement that many managers share and that is well portrayed in articles in the field; see for instance, Simpson et al. 2012).

Managers' perception of their operating environment interacts with the ways in which they organize and process information. It is very difficult for individuals to process large volumes of incoming information comprehensively, so theories of managerial cognition (Stubbart 1989) suggest that managers utilize habitual ways of organizing and processing information to adjust to these complex information processing demands. This contradicts a situational perspective when it suggests that managers do not use a broad behavioural repertoire in order to cope with the complex everyday life of managing a small firm. Another way of describing the limited use of different behaviours by small firm managers is the use of a simplistic strategy-making process, which Verreynne (2006) found is the most commonly used strategy in small firms. The simplistic strategy-making process is defined by Lumpkin and Dess (1995, p. 1386) as 'an overemphasis on the very things that made them successful in the first place'. This is also referred to as the informal strategic management mode (Mintzberg 1978 and Charles et al. 2015).

So, managers in slow-growing firms seem to use a more habitual behaviour, representing a more limited behavioural repertoire, and this might explain their more limited ability to respond to the external environment context and might shed some light on why they do not grow. This implies that managers having a broad behavioural repertoire and performing different roles frequently will perform better than their peers having a simplistic strategy-making process, which is characterized by a lack of variance in the behaviour of the manager.

In daily life, this means the managers in slow-growing firms take on to a larger extent a specialist or substitute role working mainly with a few tasks such as the firm's competitive advantage. As the dominant leader, even though he/she completes many tasks during the workday, the manager has a narrow focus of attention, often on a single goal or strategy, that is a low differentiation in the manager's attention. Dess et al. (1997, p. 686) make this point when they write that a manager in their study has 'a blueprint set some time ago that has changed very little'. In adopting the simplistic strategy, managers often neglect other important factors because of this single-focus goal. They are 'stuck' in a path-dependency mindset, even though the development of the firm might require another strategy taken by the manager. On the other hand, managers who show a broad behavioural repertoire and perform different roles frequently will be more successful when they can adopt better to different situations. According to the strategic management literature, fast-growing firms seems to be more successful in adopting management strategies that are 
suited to the environment in which they are applied (Parker et al. 2010), which suggests that these managers have a broad behavioural repertoire.

This study addresses the following key research questions:

1. Do managers in fast-growing firms possess a larger behavioural repertoire than managers in slow-growing firms?

2. Do managers in slow-growing firms possess a more limited and habitual behavioural repertoire than managers in fast-growing firms?

3. Can the larger behavioural repertoire explain why managers in fast-growing firms have the ability to take decisions that could explain growth of the firm?

4. Can the behaviour of the small-firm manager explain why it is hard for small firms to grow?

\section{Results and discussion}

From observations of the actual behaviours of the managers, they have been inductively classified to 13 main functions that the managers perform. Then, the variety (that is the variance and differentiation) of the functions between the two groups, the external and internal orientation and the dominance in the behaviour of the manager, has been studied in order to see what managers in fast-growing firms do differently from managers in slow-growing firms.

The analysis of the strategic behaviour of the managers has been done in two steps. First, after three rounds of classifications of the approximately 2500 activities, a decision on a final classification of three main activities has been done, that is, strategic, administrative, and operational activities. Within these main activities, 13 sub-activities have been identified (see Fig. 1).

Strategic activities are activities in which the managers work with important, longterm decisions related to the company's future. Administrative activities relate to support areas such as finance, administration, and personnel. Operational activities relate to the daily work of production, including purchasing, manufacturing, marketing/sales, and delivery.

In the second step of the analysis, the variety has been examined (that is, the variance and differentiation) of the 13 sub-activities at the individual and the group levels, the manager's external and internal orientation, and the manager's leadership dominance.

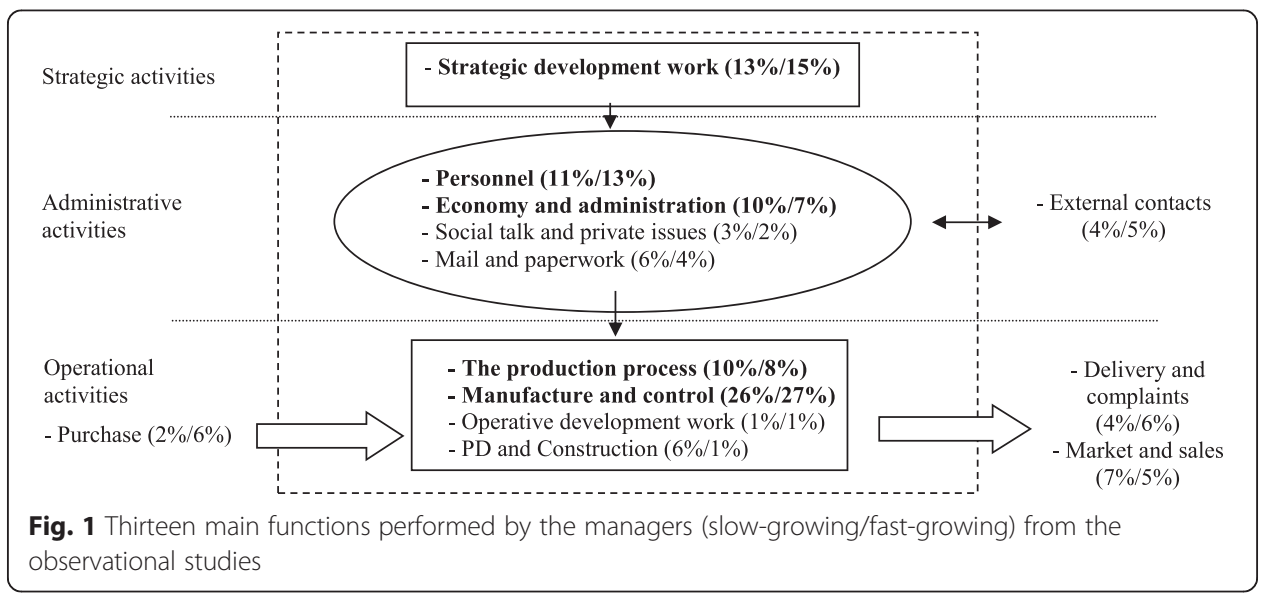


The purpose was to determine the percentage of time the managers spent on each subactivity in order to identify their main strategy according to the typology developed.

Coming back to the two first key research questions, the findings show that managers in fast-growing firms do not possess a larger behavioural repertoire than managers in slow-growing firms. Neither do managers in slow-growing firms possess a more limited and habitual behavioural repertoire than managers in fast-growing firms.

What instead becomes obvious when studying the different functions carried out by the two groups of managers is that there are more similarities than differences. The variety (that is the variance and differentiation) between the functions fluctuates very little.

Three functions or management roles (Mintzberg 1973) take up most of the manager's time and are the same for both groups, and they are as follows: manufacture and control (monitor), working with personnel-related questions (leader), and strategic development work (entrepreneur) taking up $50 \%$ of the time in slow-growing firms and $55 \%$ percent of the time in fast-growing firms. When looking at five of their functions that they work most with, economy and administration take up $10 \%$ (slow-growing firms) and $7 \%$ (fast-growing firms) of the time, respectively, and the production process takes up $10 \%$ (slow-growing firms) and $8 \%$ (fast-growing firms) of the time, respectively. This then adds up to exactly the same distribution of time and functions carried out by the managers, which is $70 \%$ of the time they spend on the same five functions. That is, the variety of tasks and the differentiation are the same between the groups.

The remaining eight functions that make up the last $30 \%$ of the managers time are also equally distributed, with very few differences, as shown in Fig. 1. These functions consist of generic small-firm managerial work such as the following: market and sales, the handling of delivery and complaints, external contacts, the purchase of all kind of material, product development (PD) and construction work, operative development work, mail and paperwork, and social talk and private issues. The numbers of internal contacts are also almost identical between the two groups.

This also means that the focus on operational, administrative, and strategic activities is the same between the two groups-that is, approximately $55 \%$ of the time is spent on operational activities, $30 \%$ on administrative activities, and $15 \%$ on strategic issues. The conclusion is that although managers perform many activities during the workday, they narrowly focus on a few activities. This suggests that there is a low variance/differentiation in behaviour as the managers prioritize some activities over others, which suggests the use of limited and habitual behaviour (as discussed by for instance by Verreynne (2006)).

The finding that slow and fast-growing firms have more similarities than differences is built on almost 20,000 min of observational studies and connects to the last two key research questions. First, the study shows that managers in fast-growing firms do not have a larger behavioural repertoire than slow-growing firms that could explain growth of the firm. Neither could the behaviour of the small-firm manager explain why it is hard for small firms to grow.

The findings, however, raise some interesting reflections and further questions. One question is if it really matters what the top-manager does or is the growth just built on luck or external forces out of their control? Another reflection is whether the work of the topmanager in small firms is so generic that only a minority of the hours per week are spent on activities that generate a difference in value, or whether the method of observation is not precise enough in catching the unique features of leadership in small growing firms? 


\section{Conclusions}

Research on small-firm growth clearly indicates that firm growth presupposes that the degree of formalization will increase (Greiner 1972; Mintzberg 1983). It therefore could be expected that managers in fast-growing firms work more with strategic and administrative questions than operational questions when the company grows. However, it is important to take into consideration that the majority of the small firms do not want to grow due to 'the managers' perception of how feasible and desirable the strategy is and their propensity to follow this course of action' (Mazzarol et al. 2009, p. 323). Many firms are survival-oriented firms that are controlled by a family and are seen as providing a small income, but the managers see that growth might jeopardize the existence of the firm (Poutziouris 2003). One expectation is, therefore, that there ought to be differences between how fast-growing and slow-growing firms are led by the managers.

One interesting conclusion in the study is, therefore, that due to the generic features of managerial work, managers in small manufacturing companies, irrespective of whether they grow or not, engage in similar activities that take almost $90 \%$ (30 \% administrative, $55 \%$ operational) of their time. A total of approx. $15 \%$ of the manager's time is spent on strategic activities, and when there is no difference in the length of time spent between the managers in the two studied groups, as well as no difference in the variation or differentiation of their focus on different activities, it seems that managerial behaviour cannot explain the difference in growth between firms.

Another conclusion of this study is that the managers in slow-growing firms find it hard to let go of the very thing (e.g. operational issues such as production processes) that caused the firm to grow initially (a simplistic strategy). There may be a strong tendency towards path-dependent behaviour by managers. Parker et al. (2010, p. 223) state that 'firms are unlikely to be successful if they attempt to draw lessons from observing growth in one period and applying these lessons routinely at a different point in time'. Imitating past managerial policy may result in future inflexibility with little innovation. As Leitner and Güldenberg (2010) claim, a small firm requires a combined strategy of innovativeness and efficiency. However, under the constraint of scarce resources typical of small firms, it is difficult for the top managers to change their behaviour in order to find time to focus on strategic issues. The small firm that was once fast-growing may be stuck in the paradox of its own success. Such success, as Elsass (1993, p. 84) writes, makes 'organizations lose the ability to recognize and respond to environmental demands'. This could be seen in the growth patterns of fast-growing firms, where the growth rate is substantially lower in the 5 years after the first growth period, and even this growth pattern is non-linear rather than linear. Parker et al. (2010) claim these findings follow Gibrat's rule of proportionate growth: growth is not serially correlated but randomly distributed. As a result, the typical gazelle growth pattern is a short spurt of growth followed by a return to the industry average growth rate (Acs and Mueller 2008).

\section{Practical implications}

For managers, the findings imply the need to take one step back and reflect on the way the firm is managed and find a better balance between innovativeness, meaning having a broad behavioural repertoire to be able to see and respond to different situational contexts, and efficiency, using a habitual response, representing a more limited behavioural repertoire, in order to be cost effective. One way to create this possibility for 
reflection is to engage in critical dialogues not only with suppliers and customers, but also with intermediates and universities in different network constellations (see for instance Street and Cameron (2007) or Laforet (2011)), in order to get new perspectives. This is sometimes referred to as a specific type of dynamic capability, that is, 'the capacity to purposefully create, extend, or modify the firm's resource base, augmented to include the resources of it alliance partners' (Furlan et al. 2014, p. 35).

In the field of managerial development, collaborative learning in so-called learning networks has been found to be one way to overcome internally the problem of scarce resources. Learning networks are defined as 'network(s) formally set up for the primary purpose of increasing knowledge, expressed as an increased capacity to do something' (Bessant and Francis 1999, p. 377). A learning network could be understood as a platform for conversations/talks, reflection, and sense-making, where managers come together in a non-competitive environment to discuss and reflect upon different issues in their day-to-day work. The learning network approach is, in this respect, a highly interactive pedagogical model where participants are encouraged to discuss different issues related to their own organizations. These actors provide a non-hierarchical arena for experience exchange and learning, which is expected to increase entrepreneurs' abilities to take advantage of business opportunities. This could help the managers overcome the difficulties to find a better balance between innovativeness and to be cost effective.

\section{Future research directions}

The finding that very little time is spent on strategic work and the weak correlation to growth is consistent with findings from a study by Coad (2009), in which he found that in 12 reviewed studies, eight report $R^{2}$ values of below $10 \%$ and six report $R^{2}$ values of $5 \%$ or less in explaining the relationship between the growth of the firm and strategic work by top management in small firms. ${ }^{2}$ How could this be explained?

One interesting reflection is if, over time, the behaviour of the managers in fastgrowing firms is becoming more and more generic and habitual (similar to managers in slow-growing firms) due to external and internal demands on the firm, as well as the situation when the managers become more experienced. The managers' perception of their operating environment interacts with the ways in which they organize and process information, and managers utilize more and more habitual and limited ways of organizing information after a while to adjust to the complex information processing demands. Also, what Mazzarol et al. (2009) refer to as strategic myopia, a condition characterized by a short-sighted focus on the daily operational matters, makes most mangers gravitate to a similar behaviour. Here, experience is negative only when it seems to hamper the innovativeness ${ }^{3}$ of the firm and thus the capability to grow. This could explain why growth in many firms comes to a halt after a couple of years (Coad 2009).

One future research direction is to develop the method of studying further, by gathering managers (of slow- and fast-growing firms) and conducting an experiment as Isenberg (1986) did. He asked two different groups (experienced managers and students) to think aloud about how to solve different business cases. If one uses the same approach in comparing the behaviour of managers in slow- and fast-growing firms, solving different cases or situations they face in their daily work in simulated situations, this method might find the unique features of leadership in small growing firms not seen in the use of observations. 
- Growth should be organic and not by acquisition

The slow-growing firms represent the typical firm, which has almost no growth at all. There is a danger in this study's approach to exploring the relationship between managerial behaviour and small-firm growth. The danger is that the conclusions from a sample population are not generalizable to a larger population owing to the number of variables influencing the results. I have therefore, together with a colleague, invested time and effort in identifying small manufacturing firms that have similar characteristics in order to keep as many variables as possible constant.

An advantage of direct observation compared to interviews is that observational data are less subject to participant constraint and interpretation. It is, however, necessary to consider the 'researcher effect' (or the 'Hawthorne effect' as it is often labelled). Although this effect is neither avoidable nor measureable, it is important to recognize that the presence of the researcher in observations may affect the data and the research results. In this research, I dealt with possible distortions from the researcher effect by frank discussions with the managers, both individually and in groups.

\section{Endnotes}

${ }^{1} \mathrm{~A}$ number of definitions of small firms are available. In this article, I use the definition by Storey (1994), in which a small firm employs 10 to 99 employees.

${ }^{2}$ [Beaver (2007):12] suggests four reasons that many small firm managers do not work with the strategy process: not enough time, unfamiliarity with strategic management techniques and processes, lack of skills, and lack of trust and openness.

${ }^{3}$ Innovativeness reflects a firm's tendency to engage in and support new ideas, novelty, experimentation, and creative processes that may result in new products, services, or technological processes (Lumpkin and Dess 1996).

${ }^{4}$ For a thorough description of the use of this methodology, see Mintzberg (1973), Appendix.

\section{Appendix}

Table 2 Chronological record

\begin{tabular}{llll}
\hline Chronological record & Date: & Managers name: \\
\cline { 3 - 4 } Time of day & Medium & Reference & Time (min) \\
\hline
\end{tabular}

Table 3 Mail record

\begin{tabular}{|c|c|c|c|c|c|}
\hline \multicolumn{2}{|l|}{ Mail record } & \multirow{2}{*}{$\begin{array}{l}\text { Date: } \\
\text { Sender/-recipient }\end{array}$} & \multicolumn{3}{|c|}{ Managers name: } \\
\hline Reference & Form & & Purpose & Measure & Action \\
\hline
\end{tabular}


Table 4 Contact record

\begin{tabular}{|c|c|c|c|c|c|c|}
\hline \multicolumn{2}{|c|}{ Contact record } & \multirow{2}{*}{$\begin{array}{l}\text { Date: } \\
\text { Purpose }\end{array}$} & \multicolumn{4}{|c|}{ Managers name: } \\
\hline Reference & Medium & & Participants & Initiative & Time (min.) & Place \\
\hline
\end{tabular}

\section{Competing interest}

The author declares that he has no competing interests.

\section{Authors' information}

Joakim Tell is Associate Professor in Industrial Management at the School of Business and Engineering, Halmstad University. His research interests include the development of different action technologies, such as learning networks, managerial behaviour in small enterprises, business simulations, and leadership and learning issues in general.

\section{Acknowledgements}

The author is grateful for the financial support from the Knowledge Foundation (KK-stiftelsen) in Sweden. I also want to express my appreciation to the journal's editor and reviewers for their excellent support.

This research was financed by grants from the Knowledge Foundation (KK-stiftelsen).

Received: 4 June 2015 Accepted: 26 October 2015

Published online: 04 November 2015

\section{References}

Acs, Z. J., \& Mueller, P. (2008). Employment effects of business dynamics: mice, gazelles and elephants. Small Business Economics, 30(1), 85-100.

Andersson, S., \& Tell, J. (2009). The relationship between the manager and growth in small firms. Journal of small business and Enterprise Development, 16(4), 586-598.

Beaver, G. (2007). The strategy payoff for smaller enterprises. The Journal of Business Strategy, 28(1), 11-17.

Bessant, J., \& Francis, J. (1999). Using learning networks to help improve manufacturing competitiveness. Technovation, 19(6/7), 373-381.

Birch, D. (1979). Job generation process. Cambridge, MA: Joint Center for Neighborhood and Regional Development, MIT.

Carpenter, M., Geletkanycz, M., \& Sanders, G. (2004). Upper echelons research revisited: antecedents, elements, and consequences of top management team composition. Journal of Management, 30(6), 749-778.

Charles, NA, Ojera, PB, \& David, O (2015). Factors influencing choice of strategic management modes of small enterprises. Journal of Innovation and Entrepreneurship, 4(4): Open access.

Choran, I. (1969). The manager of a small company (Thesis). Montreal: McGill University, Unpublished M.B.A.

Coad, A. (2009). The growth of firms: a survey of theories and empirical evidence. Cheltenham: Edward Elgar.

Covin, J., \& Slevin, P. (1989). Strategic management of small firms in hostile and benign environments. Strategic Management Journal, 10(1), 75-87.

Davidsson, P. (1992). Environment and entrepreneurship: culture, structure, and new firm formation rates in Sweden. Singapore: Paper presented at the ENDEC World Conference on Entrepreneurship.

Day, D. V., \& Lord, R. G. (1988). Executive leadership and organizational performance: suggestions for a new theory and methodology. Journal of Management, 14(3), 453-464.

Denison, D., Hooijberg, R., \& Quinn, R. (1995). Paradox and performance: toward a theory of behavioral complexity in managerial leadership. Organization Science, 6(5), 524-541.

Dess, G., Lumpkin, G., \& Covin, J. (1997). Entrepreneurial strategy making and firm performance: tests of contingency and configurational models'. Strategic Management Journal, 18(9), 677-695.

Elsass, P. (1993). The paradox of success: too much of a good thing? Academy of Management Executive, 7(3), 84-85.

Florén, H., \& Tell, J. (2004). The emergent prerequisites of managerial learning in small firm networks. Leadership \& Organization Development Journal, 25(3/4), 292-307.

Furlan, A., Grandinetti, R., \& Paggiaro, A. (2014). Unveiling the growth process: entrepreneurial growth and the use of external resources. International Journal of Entrepreneurial Behaviour \& Research, 20(1), 20-41.

Gartner, W. B. (1988). Who is an entrepreneur is the wrong question. Entrepreneurship Theory and Practice, 13(1), 47-64.

Gartner, W. B., Bird, B. J., \& Starr, J. A. (1992). Acting as if: differentiating entrepreneurial from organizational behaviour. Entrepreneurship Theory and Practice, 16(3), 13-31.

Greiner, L. E. (1972). Evolution and revolution as organizations grow. Harvard Business Review, 50(4), 37-45.

Hales, C. P. (1986). What do managers do? A critical examination of the evidence. Journal of Management Studies, 23(1), $88-115$.

Hambrick, D. C., \& Mason, P. A. (1984). Upper echelons: the organization as a reflection of its top managers. Academy of Management Review, 9(2), 193-206.

Hendrickson, L., \& Psarouthakis, J. (1998). Dynamic management of growing firms: a strategic approach. Ann Arbor: The University of Michigan Press.

Hooijberg, R. (1996). A multidirectional approach toward leadership: an extension of the concept of behavioral complexity. Human Relations, 49(7), 917-947.

Hooijberg, R., \& Choi, J. (2001). The impact of organizational characteristics on leadership effectiveness models: an examination of leadership in a private and a public sector organization. Administration \& Society, 33(4), 403-32. 
Houmanfar, R., Rodrigues, N., \& Smith, G. (2009). Role of communication networks in behavioural systems analysis. Journal of Organizational Behaviour and Management, 29(3/4), 257-275.

Iraj, H., \& Besnik, A. (2011). Entrepreneurship and SME growth: evidence from advanced and laggard transition economies. International Journal of Entrepreneurial Behaviour \& Research, 17(5), 456-487.

Isenberg, D. (1986). Thinking and managing: a verbal protocol analysis of managerial problem solving. Academy of Management, 29(4), 775-788.

Kotter, J. (1982). What effective general managers really do. Harvard Business Review, 60(2), 157-169.

Laforet, S. (2011). A framework of organisational innovation and outcomes in SMEs. International Journal of Entrepreneurial Behaviour \& Research, 17(4), 380-408.

Leitner, K.H., \& Güldenberg, S. (2010). Generic strategies and firm performance in SMEs: a longitudinal study of Austrian SMEs. Small Business Economics, 35(2), 169-189.

Lumpkin, G. T., \& Dess, G. G. (1995). Simplicity as a strategy making process: the effects of stage of organizational development and environment on performance. Academy of Management Journal, 38(5), 1386-1407.

Lumpkin, G. T., \& Dess, G. G. (1996). Clarifying the entrepreneurial orientation construct and linking it to performance. Academy of Management Review, 21(1), 135-172

Mazzarol, T., Reboud, S., \& Soutar, G. (2009). Strategic planning in growth oriented small firms. International Journal of Entrepreneurial Behaviour \& Research, 15(4), 320-345.

Mintzberg, H. (1973). The nature of managerial work. New York: Harper \& Row.

Mintzberg, H. (1978). Patterns in strategy formulation. Management Science, 24(9), 935-948.

Mintzberg, H. (1983). Structure in fives: designing effective organizations. Englewood Cliffs, NJ: Prentice-Hall.

Morrison, A., Breen, J., \& Ali, S. (2003). Small business growth: Intention, ability, and opportunity. Journal of Small Business Management, 41(4), 417-425.

Noel, A. (1989). Strategic cores and magnificent obsessions: discovering strategy formation through daily activities of CEOS. Strategic Management Journal, 10(1), 33-49.

O'Gorman, C. (2001). The sustainability of growth in small- and medium-sized enterprises. International Journal of Entrepreneurial Behaviour \& Research, 7(2), 60-75.

Parker, S., Storey, D., \& Witteloostuijn, A. (2010). What happens to gazelles? The importance of dynamic management strategy'. Small Business Economics, 35(2), 203-226.

Pelham, A., \& Wilsson, D. (1995). A longitudinal study of the impact of market structure, firm structure, strategy, and market orientation culture on dimensions of small-firm performance. Journal of the Academy of Marketing Science, 24(1), 27-43.

Poutziouris, P. (2003). The strategic orientation of owner-managers of small ventures-evidence from the UK small business economy. International Journal of Entrepreneurial Behaviour \& Research, 9(5), 185-214.

Quinn, R., McGrath, M., Blake, R., \& Mouton, J. (1982). Moving beyond the single-solution perspective: the competing values approach as a diagnostic tool. Comment rejoinder. The Journal of Applied Behavioral Science, 18(4), 463-480.

Russel, G. R., Weber, P. B., \& Laetz, V. B. (1994). Linking small business management with entrepreneurial growth. Journal of Small Business Management, 32(4), 48-60.

Sadler-Smith, E., Hampson, Y., Chaston, I., \& Badger, B. (2003). Managerial behaviour, entrepreneurial style, and small firm performance. Journal of Small Business Management, 41(1), 47-67.

Sarasvathy, S. D. (2001). Causation and effectuation: toward a theoretical shift from economic inevitability to entrepreneurial contingency. Academy of Management Review, 26(2), 243-263.

Simpson, M., Padmore, J., \& Newman, N. (2012). Towards a new model of success and performance in SMEs. International Journal of Entrepreneurial Behaviour \& Research, 18(3), 264-285.

Slevin, D., \& Covin, J. (1990). Juggling entrepreneurial style and organizational structure. Sloan Management Review, $31(2), 43-54$.

Storey, D. J. (1994). Understanding the small business sector. London: Routledge.

Street, C., \& Cameron, A. (2007). External relationships and the small business: a review of small business alliance and network research. Journal of Small Business Management, 45(2), 239-267.

Stubbart, C. (1989). Managerial cognition: a missing link in strategic management research. Journal of Management Studies, 26(4), 325-347.

Thomas, A. B. (1988). Does leadership make a difference to organizational performance? Administrative Science Quarterly, 33(3), 388-400.

Tipu, S., \& Arain, F. (2011). Managing success factors in entrepreneurial ventures: a behavioral approach. International Journal of Entrepreneurial Behaviour \& Research, 17(5), 534-560.

Verreynne, M. L. (2006). Strategy-making process and firm performance in small firms. Journal of Management and Organization, 12(3), 209-222.

Wiklund, J. (1998). Small firm growth and performance (Doctoral Thesis). Sweden: Jönköping International Business School, Jönköping University.

Wiklund, J., \& Shephard, D. (2003). Aspiring for, and achieving growth: the moderating role of resources and opportunities. Journal of Management Studies, 40(8), 1919-1941. 